\title{
Acute lymphoblastic leukemia in a child with Leri-Weill syndrome and complete SHOX gene deletion: A Case Report
}

\author{
Jana Volejnikova ${ }^{\mathrm{a}, \mathrm{b}}$, Jirina Zapletalova ${ }^{\mathrm{a}}$, Marie Jarosovac, Helena Urbankovac, Petr Vojta ${ }^{\mathrm{b}}$, Eva Klaskovaa \\ Marshall S. Horwitz ${ }^{\mathrm{d}}$, Marian Hajduch ${ }^{\mathrm{b}}$, Vladimir Mihala ${ }^{\mathrm{a}, \mathrm{b}}$
}

\begin{abstract}
Background. Leri-Weill syndrome (LWS) ranks among conditions with short stature homeobox gene (SHOX) haploinsufficiency. Data on possible association of SHOX aberrations with malignant diseases are scarce.

Methods and Results. We report a unique case of an 8-year-old girl who was successfully treated for acute lymphoblastic leukemia (pre-B ALL, intermediate risk) and was subsequently diagnosed with LWS due to characteristic clinical appearance (short disproportionate stature, Madelung deformity of the wrist) and molecular genetic examination (complete deletion of SHOX). An identical SHOX deletion was identified also in the patient's mother. Leukemic cells of the patient were retrospectively examined by array comparative genomic hybridization (aCGH), which revealed five regions of deletions at chromosome $X$, including the SHOX gene locus.

Conclusion. Growth retardation in children with hemato-oncologic malignancies cannot always be attributed to cytotoxic treatment and should be carefully evaluated, especially with regards to growth hormone therapy.

Key words: acute lymphoblastic leukemia (ALL), childhood, Leri-Weill syndrome (LWS), pseudoautosomal region (PAR1), SHOX gene

Received: January 23, 2017; Accepted with revision: February 5, 2018; Available online: February 21, 2018 https://doi.org/10.5507/bp.2018.002

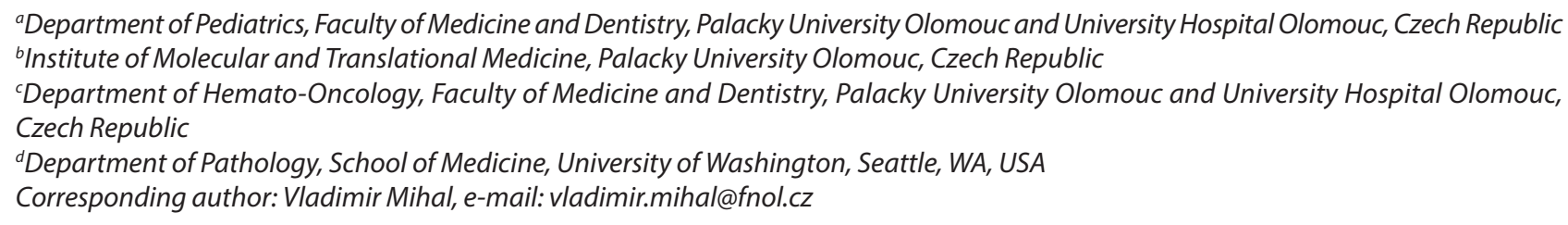

\section{INTRODUCTION}

Leri-Weill syndrome or Léri-Weill dyschondrosteosis (LWS), first described in 1929 (ref. ${ }^{1}$ ), is a rare pseudoautosomal dominant genetic disorder characterized by skeletal dysplasia with disproportionate short stature, mesomelia (i.e. shortening of the middle parts of the limbs) and characteristic Madelung wrist deformity ${ }^{2}$. LWS is caused by mutations of the short stature homeobox ( $S H O X)$ gene located within the pseudoautosomal region (PAR1) of both sex chromosomes (Xp22 and Yp11). SHOX haploinsufficiency was reported as causative for short stature in women with Turner syndrome ${ }^{3}$ and subsequently its mutations have been identified in patients with LWS and Langer mesomelic dysplasia ${ }^{4,5}$ and in approximately $2-16 \%$ of cases with idiopathic (nonsyndromic) short stature including children born small for gestational age ${ }^{3,6-9}$. SHOX abnormalities have been associated with various physical features such as scoliosis, increased carrying angle of the elbow, deformities of the forearm and tibiae, shortening of the fourth and fifth metacarpals, malformations of the middle ear, exostoses, high-arched palate, micrognathia and muscular hypertrophy ${ }^{8}$. Mutations of other genes located within Xp22.3 cause monogenic X-linked syndromes such as Kallmann syndrome, chondrodysplasia punctata, ichthyosis and learning/behavioral difficulties ${ }^{10,11}$.
Much attention has been paid to $S H O X$ as one of the main growth regulators, however, less is known about its association with other pathological conditions, such as disorders of hematopoiesis and malignant tumors. Here we report a unique case of coincidence of LWS and acute lymphoblastic leukemia (ALL).

\section{CASE REPORT}

An 8-year-old female was diagnosed with ALL (L2 morphology, pre-B immunophenotype, prednisone good response, classified into the intermediate risk group). The karyotype of the leukemic cells was 46,XX,del(X) (Xp22.33--Xp21.3::Xp 11.1--Xq22.2::Xqter),t(12;21) (p13;q22)[15]/46,XX[6]. Fluorescence in situ hybridization (FISH) using SHOX region probe (MD Short Stature (Xp22)/SE X (Kreatech, Amsterdam, Netherlands) showed two unrearranged signals with both Xp and centromeric regions retained; however, five regions of deletion comprising the SHOX gene locus and one region of loss of heterozygosity $(\mathrm{LOH})$ were detected by array comparative genomic hybridization (aCGH, SurePrint G3 Human CGH+SNP Platform, 4x180K, data analysis CytoGenomic software, both Agilent, Santa Clara, CA, USA). Furthermore, deletion in 3p24.1, 7p14.3 and mono- 


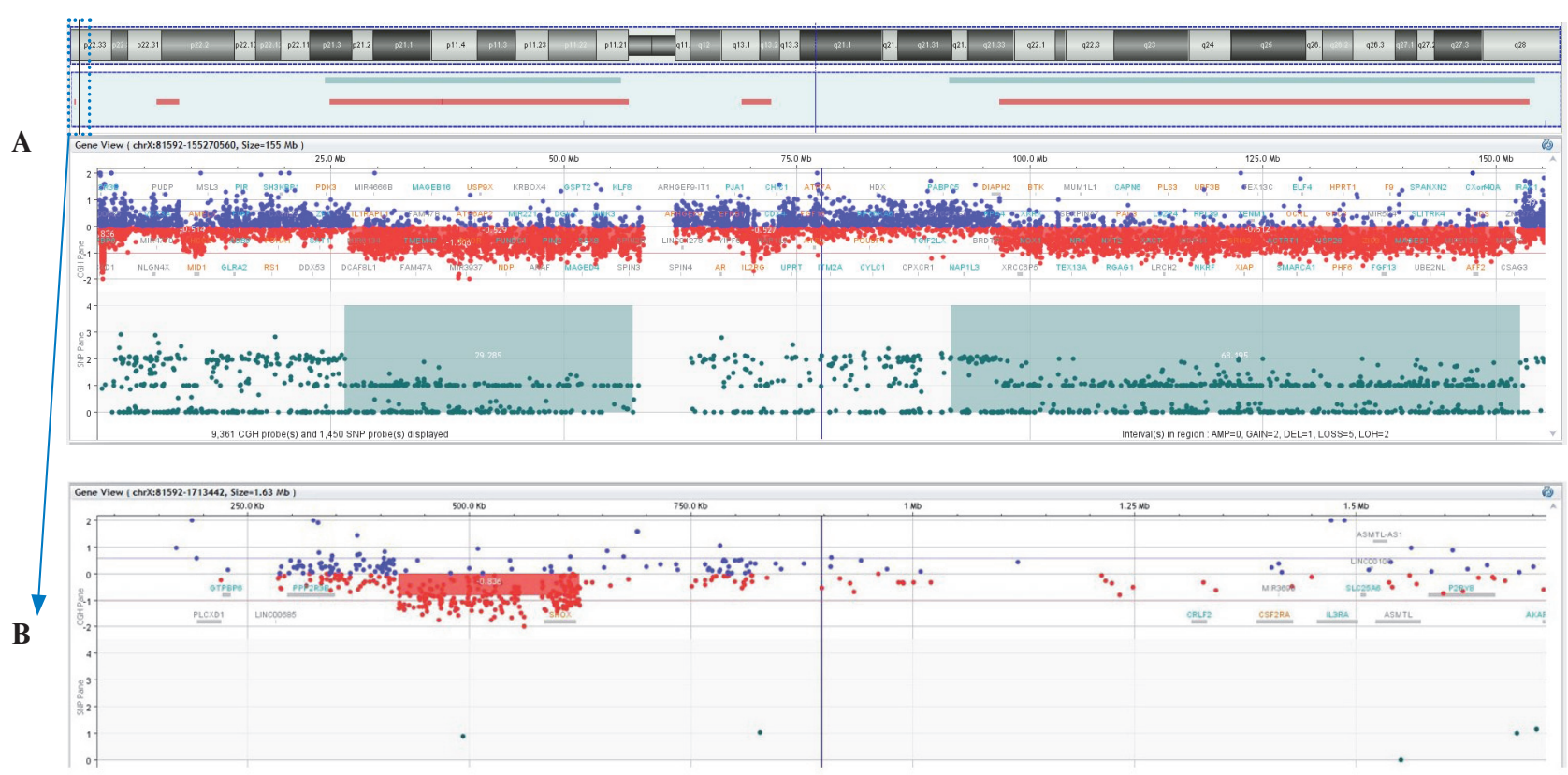

Fig. 1. Chromosome $\mathrm{X}$ in leukemic cells of patient with Leri-Weill syndrome. A) Ideogram and aCGH $\log 2$ ratio plot of chromosome X displaying 5 regions of deletion (red lines) at Xp22.33, Xp22.31p22.2, Xp21.3p11.1, Xq13.1q13.2 and Xq21.33q28 (CGH Pane) and SNP array result showing the number of uncut alleles and LOH region Xq21.31q21.33 (grey line, SNP Pane). B) Detail of the Xp22.33 region (81592-1713442).

and biallelic deletions involving the retinoblastoma gene $(R B 1)$ on chromosome $13 \mathrm{q}$ were present. The result of aCGH in leukemic cells was $\operatorname{arr}[$ hg 19] 3p24.1(27139147_29312423)x1, 7p14.3(30821635_31233233)x1, 13q12.3q14.3(31729646_53436659)x1, 13q14.2(48985982_49150225)x0, Xp22.33(420237_624896)x1, Xp22.31p22.2(9053476_11401244)x1, Xp21.3p11.1(27034198_58188680)x1, Xq13.1q13.2(69960578_73063439)x1, Xq21.31q21.33(87981878_96791827)x2 hmz, Xq21.33q28(96829124_152053777)x1 (Fig. 1). The list of involved genes is given in Table 1 . The aCGH datasets are available from the NCBI Gene Expression Omnibus (GEO) repository: http://www.ncbi.nlm.nih. gov/geo/query/acc.cgi?acc $=$ GSE110235. The patient was successfully treated at our department with the ALLBFM 95 protocol. She is alive in first complete remission and has experienced no long term sequelae to the ALL therapy.

Nevertheless, at the regular follow-up examination at the age of 11 years, disproportionate short stature with shortening of the forearms and tibia and muscular hypertrophy were recognized (Fig. 2). The patient's height at the age of 11 years was $127 \mathrm{~cm}$ (-2.5 standard deviation (SD), Fig. 3). On wrist X-ray, the skeletal age was accelerated by 1 year and Madelung deformity was detected (Fig. 4).

The patient's history was reviewed: she was delivered at term with a normal birth weight (3000 g) and birth length $(52 \mathrm{~cm})$. Her psychomotor development was normal. However, her growth curve since early childhood was following the approximately $-2.5 \mathrm{SD}$ percentile of the
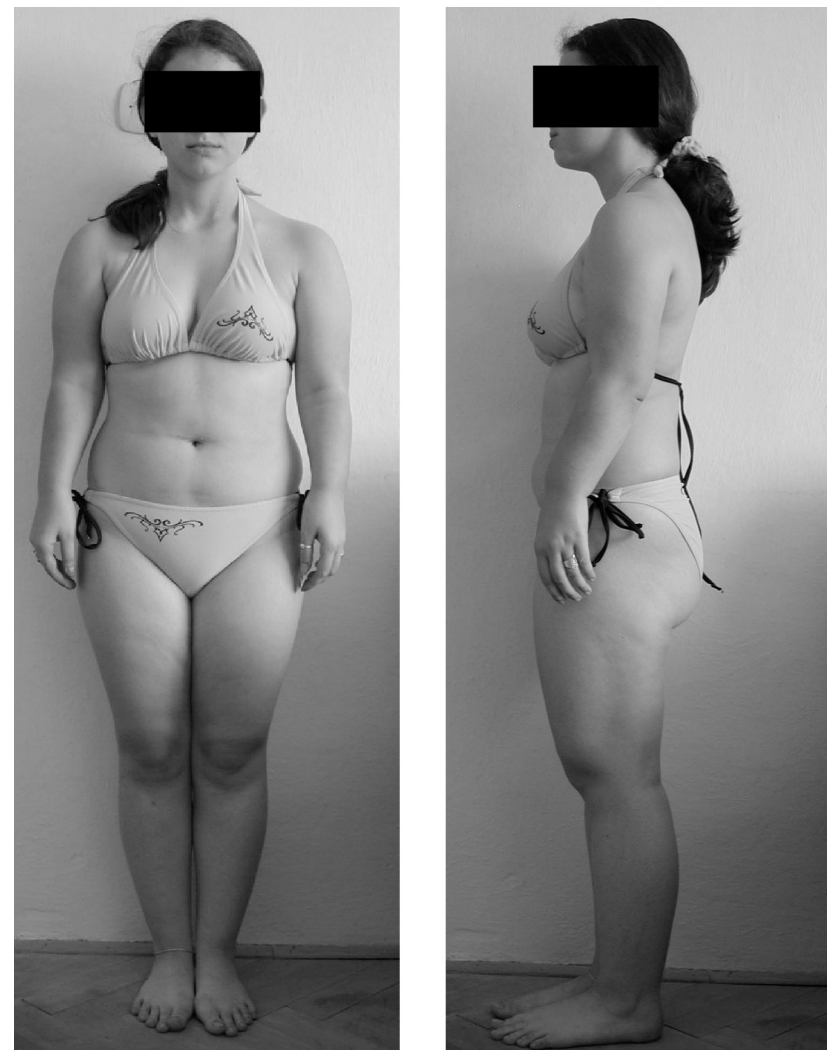

Fig. 2. Short disproportionate stature in a patient with LeriWeill syndrome and ALL. The patient had an adult height of $147.7 \mathrm{~cm}$ (picture taken at the age of 15 years). Note shortening of forearms and tibia and muscular hypertrophy. 


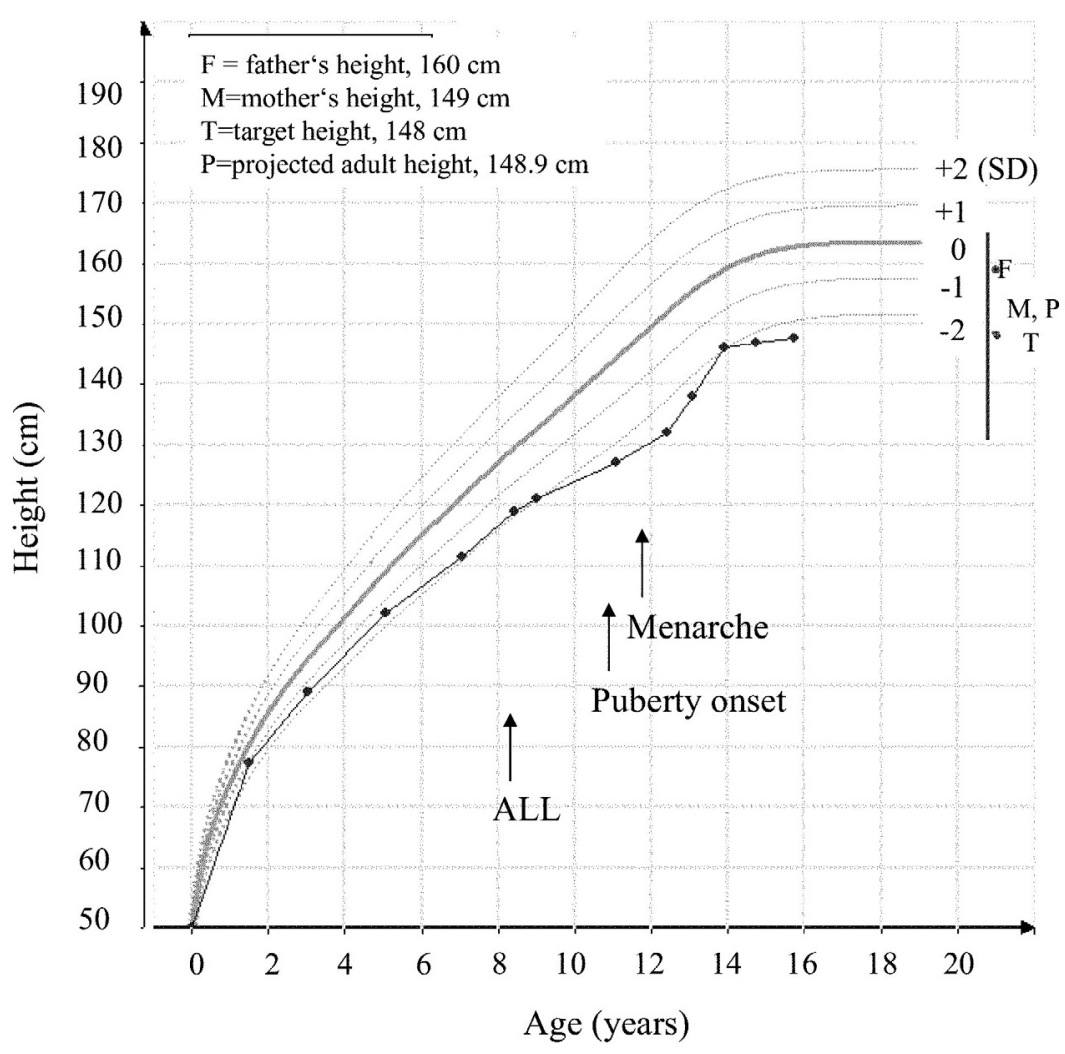

Fig. 3. Growth curve of patient with Leri-Weill syndrome and ALL. Growth charts by Freeman et al., 1995. F, father's height; M, mother's height; T, target (estimated) height.

national height standards. This had been previously attributed to a familial disposition; the patient's parents also had short stature: mother $149.2 \mathrm{~cm}(-2.6 \mathrm{SD})$, maternal grandmother $150 \mathrm{~cm}$ and father $160 \mathrm{~cm}(-2.4 \mathrm{SD}$, Fig. 3).

Mutations and deletions in the SHOX gene were examined in peripheral blood using polymerase chain reaction (PCR), heteroduplex formation, single nucleotide polymorphism (SNP)-based detection by denaturing high-pressure liquid chromatography (DHPLC) and sequencing (SHOX-DNA-Dx, Esoterix, CA, USA; www. esoterix.com). Complete deletion of the SHOX gene was confirmed. Despite the fact that there was an ongoing clinical trial with growth hormone in 2001, the patient did not receive the treatment due to late diagnosis. She had an early onset of puberty (at 11 years) and at the time of LWS diagnosis her Tanner stages were B2, Ph1, A1. The patient had menarche at the age of 11 years and 10 months and her postmenarchal growth was minimal; her final height was $147.7 \mathrm{~cm}$, i.e. approximately $-2.5 \mathrm{SD}$ (Fig. $3)$. She delivered a boy at the age of 19 years.

The suspicion of LWS was raised in the patient's mother who also displayed disproportionate short stature and Madelung deformity. Using the same molecular genetic test (SHOX-DNA-Dx, Esoterix), the identical complete deletion of the SHOX gene was confirmed.

The patient's parents provided informed consent for publication.

\section{DISCUSSION}

The list of indications for growth hormone therapy in children is increasing, with LWS being added in 2007 in the European Union. Thus, an appropriate detection of SHOX aberrations is vital for timely initiation of growth hormone treatment. Reports on SHOX status in malignant diseases are scarce. A connection between SHOX2 methylation of cell-free circulating DNA and lung cancer has been suggested; however SHOX2, unlike $S H O X$, is an autosomal homeobox gene located on chromosome 3 (ref. ${ }^{12,13}$ ). Translocations of the TFE3 transcription factor gene at Xp11 in tumor cells are related to papillary renal cell carcinoma ${ }^{14}$. Regarding disorders of hematopoiesis, a predisposing locus for Hodgkin lymphoma was placed in proximity to SHOX in PAR1. This was based on familiar coinheritance of LWS and Hodgkin lymphoma and a predominance of same-sex sibling pairs among those affected with Hodgkin disease ${ }^{15}$. Recurrent somatic mutations in P2RY8 gene located in PAR1 have been identified in cases of diffuse large B-cell lymphoma ${ }^{16}$. In an elderly male with concurrent LWS, Klinefelter syndrome and hepatocellular carcinoma followed by myelodysplastic syndrome, breakpoint regions did not involve cancer genes and thus the causality between $\operatorname{dic}(\mathrm{X} ; \mathrm{Y})(\mathrm{p} 22.33 ; \mathrm{p} 11.32)$ and mentioned malignancies was considered unlikely ${ }^{17}$.

PAR1 includes genes with an important role in immune response and hematopoiesis, such as granulocyte macrophage colony-stimulating factor receptor (CSF2RA or GM-CSFR), interleukin 3 receptor alpha (IL3RA) 
A

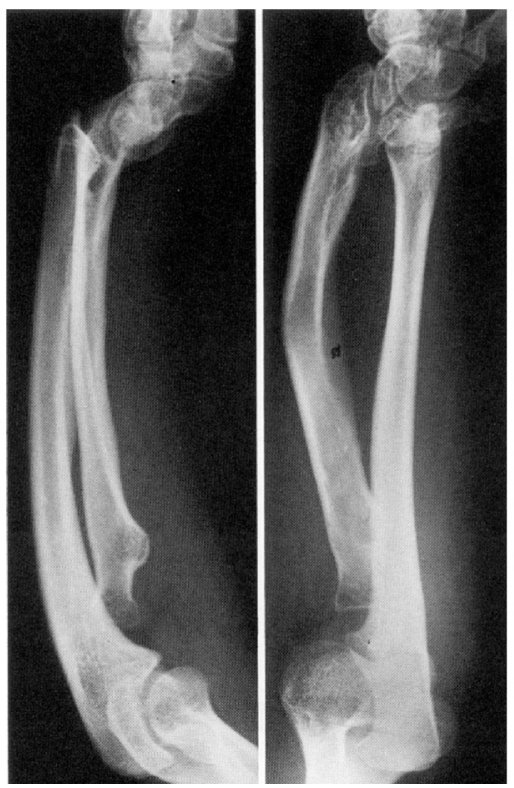

B

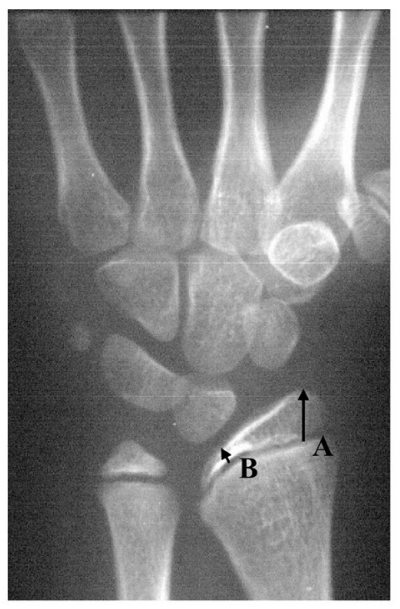

C

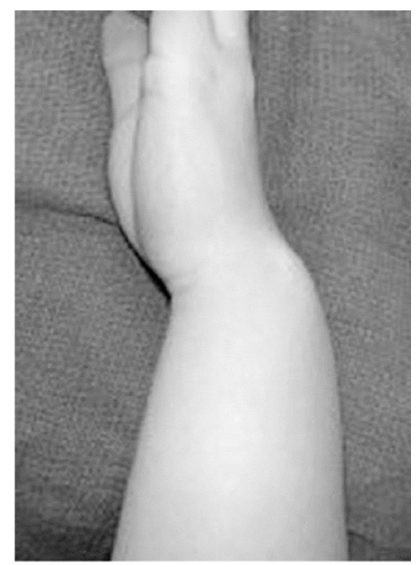

Fig. 4. Madelung deformity of the wrist. The deformity is congenital, bilateral and is characterized by growth disturbance in the volar-ulnar distal radial physis. This results in a bowing and shortening of radius and dorsal dislocation of distal ulna (A). (B) Triangulation of distal radial epiphysis with shortening of the ulnar segment (A/B index>4.0). (C) Volar translation of the hand and wrist causes restriction of movement.

Table 1. Selected genes and biological processes affected by gene deletions in leukemic cells of the patient with LWS and ALL.

\begin{tabular}{|c|c|c|c|c|c|}
\hline GO_ID & Biological Process & $\begin{array}{l}\text { Total } \\
\text { Mapped } \\
\text { Genes }\end{array}$ & $\begin{array}{l}\text { Found } \\
\text { Genes }\end{array}$ & $\begin{array}{l}\text { Fraction } \\
\text { Found/Total }\end{array}$ & Gene List \\
\hline GO:0006281 & DNA repair & 516 & 12 & 0.02 & $\begin{array}{l}\text { APEX2,BRCA2,CETN2,CUL4B,HUWE1,M } \\
\text { ORF4L2,NONO,PDS5B,RFC3,RPA4,SMC1 } \\
\text { A,UBE2A }\end{array}$ \\
\hline GO:0060215 & Primitive hemopoiesis & 9 & 1 & 0.11 & GATA1 \\
\hline GO:1903708 & Positive regulation of hemopoiesis & 163 & 10 & 0.06 & $\begin{array}{l}\text { ATP11C,BTK,FOXP3,GATA1,N4BP2L2,NK } \\
\text { AP,OGT,RB1,SASH3,TNFSF11 }\end{array}$ \\
\hline GO:0060216 & Definitive hemopoiesis & 21 & 1 & 0.05 & GATA1 \\
\hline GO:0035162 & Embryonic hemopoiesis & 22 & 1 & 0.05 & GATA1 \\
\hline GO:1903706 & Regulation of hemopoiesis & 326 & 12 & 0.04 & $\begin{array}{l}\text { ATP11C,BTK,FOXP3,GATA1,HMGB3,N4BP } \\
\text { 2L2,NKAP,OGT,RB1,SASH3,TFE3,TNFSF11 }\end{array}$ \\
\hline GO:0030097 & Hemopoiesis & 734 & 20 & 0.03 & $\begin{array}{l}\text { ALAS2,ARL11,ATP11C,AZI2,BRCA2,BTK,C } \\
\text { D40LG,EBP,EOMES,FOXP3,GATA1,GPC3, } \\
\text { HMGB3,N4BP2L,NKAP,OGT,RB1,SASH3,T } \\
\text { FE3,TNFSF11 }\end{array}$ \\
\hline GO:1903707 & Negative regulation of hemopoiesis & 131 & 3 & 0.02 & FOXP3,HMGB3,N4BP2L2 \\
\hline GO:0035603 & $\begin{array}{l}\text { Fibroblast growth factor receptor } \\
\text { signaling pathway }\end{array}$ & 1 & 0 & 0 & \\
\hline GO:0040008 & Regulation of growth & 641 & 19 & 0,03 & $\begin{array}{l}\text { AGTR2,DDX3X,ENOX2,FGF13,FHL1,GHR } \\
\text { HR,GPC3,MCTS1,MORF4L2,MTM1,NRK,P } \\
\text { SMD10,RB1,SASH3,SPG20,TRO,TRPC5,TS } \\
\text { PYL2,WWC3 }\end{array}$ \\
\hline
\end{tabular}


and cytokine receptor-like factor 2 ( $C R L F 2)$ whose rearragements resulting from deletions in PAR1 have been detected in leukemic cells in a substantial percentage (14\%) of children with ALL and reported to be associated with mutation of JAK kinases, IKZFI alterations and poor treatment outcomes ${ }^{18}$. Adverse prognostic impact of $C R L F 2$ rearrangements leading to $C R L F 2$ overexpression in children and adults with ALL has since then been confirmed by numerous studies ${ }^{19,20}$.

The $C R L F 2$ gene in leukemic cells of our patient taken at the time of ALL diagnosis was undeleted, as well as P2RY8, CSF2RA and IL3RA. False negativity of FISH for SHOX deletion was caused by the fact that the probe only partially covered the $S H O X$ gene and fluorescence was emitted from the residual part of the probe. Monoallelic SHOX deletion was confirmed by aCGH and thus the phenotype of the leukemic blasts was in this case in accordance with genotype.

Among 1184 gene loci within the deleted regions, genes involved in DNA repair, hematopoiesis and growth regulation were identified in our patient (Table 1), most importantly ARL11, BRCA2, FOXO4 and GATA1 which are associated with leukemia ${ }^{21-23}$.

The clinical significance of $13 \mathrm{q}$ deletion involving the retinoblastoma gene $(R B 1)$, a known tumor supressor gene whose numerous mutations are associated with retinoblastoma, several subtypes of sarcoma, melanoma and other types of cancer, is unknown in our patient. The role of loss or inactivation of $R B 1$ in leukemogenesis has been documented ${ }^{24}$.

Regarding muscular hypertrophy in our patient, we also considered that the involvement of the dystrophin gene $(D M D, \mathrm{Xp} 21.2-\mathrm{p} 21.1)$ within the deleted $\mathrm{Xp}$ region may be the causal aberration. However, the $D M D$ deletion was found only in leukemic cells and information on germinal $D M D$ status is missing. Furthermore, muscular hypertrophy, particularly involving calf muscles, affects up to $80 \%$ of the LWS patients ${ }^{8,25}$, which is much more frequent than in molecular dystrophy carriers. No other confirmed cases or signs of muscular dystrophy have been observed in the patient or her family members. Therefore, we assume that in this case the association of calf hypertrophy with $D M D$ gene is unlikely.

Unfortunately, the patient was later lost to follow-up, and therefore the remission sample was unavailable for aCGH examination. An absence of somatic DNA for further analyses, such as aCGH and next generation sequencing, is a significant drawback of our study.

The case presented here of concurrent LWS and ALL is the first published to date. A previously reported case of a child with thrombocytopenia and absent radii (TAR syndrome) who developed ALL (ref. ${ }^{26}$ ) is relevant; although genetically distinct, TAR syndrome similarly manifests with radial growth abnormalities and short stature. It is therefore necessary to distinguish between growth retardation as a side effect of ALL treatment, which is infrequent ${ }^{27}$, and possibly other unrelated pathological conditions. We emphasize the importance of careful evaluation of auxology and somatic morphology for timely diagnosis of $S H O X$ haploinsufficiency in children with unexplained short stature. Precise detection of SHOX abnormalities is important not only for therapeutic intervention but also for the estimation of prognosis, genetic counseling and search for other affected family members.

\section{CONCLUSION}

This is a unique report of a child diagnosed with inherited Leri-Weill syndrome (LWS) with characteristic clinical features and complete deletion of the SHOX gene in the first remission of acute lymphoblastic leukemia (ALL) at the age of 11 years. We highlight the importance of auxology and somatic morphology assessment in children with malignant disease. Growth retardation can be caused not only by chemo- or radiotherapy but also by other diseases or rare underlying syndromes in which timely treatment with growth hormone is indicated.

Acknowledgement: Supported by grants from the Czech Ministry of Education, Youth and Sports (NPU LO 1304) and Czech Ministry of Health (VES 2016-001).

Author contributions: VM, MH and MSH: study design and supervision; JV: data collection, literature search and manuscript writing; JZ, EK and VM: clinical management; MJ, HU: cytogenetics including database record; $\mathrm{PV}, \mathrm{MH}$ : data analysis, gene search. All co-authors have read the final manuscript within their respective areas of expertise and participated sufficiently in the study to take responsibility for it and accept its conclusions.

Conflicts of interest statement: The authors state that there are no conflicts of interest regarding the publication of this article.

\section{REFERENCES}

1. Léri A, Weill J. Une affection congénitale et symétrique du dévelopment osseux: La dyschondrostéose [congenital and symmetrical affecion bone development: the dyschondrosteosis]. Bull Mem Soc Med Hop Paris 1929;53:1491-4.

2. Seki A, Jinno T, Suzuki E, Takayama S, Ogata T, Fukami M. Skeletal Deformity Associated with SHOX Deficiency. Clin Pediatr Endocrinol 2014;23(3):65-72.

3. Rao E, Weiss B, Fukami M, Rump A, Niesler B, Mertz A, Muroya K, Binder G, Kirsch S, Winkelmann M, Nordsiek G, Heinrich U, Breuning MH, Ranke MB, Rosenthal A, Ogata T, Rappold GA. Pseudoautosomal deletions encompassing a novel homeobox gene cause growth failure in idiopathic short stature and Turner syndrome. Nat Genet 1997; 16(1):54-63.

4. Belin V, Cusin V, Viot G, Girlich D, Toutain A, Moncla A, Vekemans M, Le Merrer M, Munnich A, Cormier-Daire V. SHOX mutations in dyschondrosteosis (Leri-Weill syndrome). Nat Genet 1998;19(1):67-9.

5. Shears DJ, Vassal HJ, Goodman FR, Palmer RW, Reardon W, SupertiFurga A, Scambler PJ, Winter RM. Mutation and deletion of the pseudoautosomal gene SHOX cause Leri-Weill dyschondrosteosis. Nat Genet 1998;19(1):70-3.

6. Rappold GA, Fukami M, Niesler B, Schiller S, Zumkeller W, Bettendorf M, Heinrich U, Vlachopapadoupoulou E, Reinehr T, Onigata K, Ogata T. Deletions of the homeobox gene SHOX (short stature homeobox) are an important cause of growth failure in children with short stature. J Clin Endocrinol Metab 2002;87(3):1402-6.

7. Huber C, Rosilio M, Munnich A, Cormier-Daire V; French SHOX GeNeSIS Module. High incidence of SHOX anomalies in individuals with short stature. J Med Genet 2006;43(9):735-9. 
8. Rappold G, Blum WF, Shavrikova EP, Crowe BJ, Roeth R, Quigley CA, Ross JL, Niesler B. Genotypes and phenotypes in children with short stature: clinical indicators of SHOX haploinsufficiency. J Med Genet 2007;44(5):306-13.

9. Caliebe J, Broekman S, Boogaard M, Bosch CA, Ruivenkamp CA, Oostdijk W, Kant SG, Binder G, Ranke MB, Wit JM, Losekoot M. IGF1, IGF1R and SHOX mutation analysis in short children born small for gestational age and short children with normal birth size (idiopathic short stature). Horm Res Paediatr 2012;77(4):250-60.

10. Mitchell AL, Dwyer A, Pitteloud N, Quinton R. Genetic basis and variable phenotypic expression of Kallmann syndrome: towards a unifying theory. Trends Endocrinol Metab 2011;22(7):249-58.

11. Matos-Miranda C, Nimmo G, Williams B, Tysoe C, Owens M, Bale S, Braverman N. A prospective study of brachytelephalangic chondrodysplasia punctata: identification of arylsulfatase E mutations, functional analysis of novel missense alleles, and determination of potential phenocopies. Genet Med 2013;15(8):650-7.

12. Kneip C, Schmidt B, Seegebarth A, Weickmann S, Fleischhacker M Liebenberg V, Field JK, Dietrich D. SHOX2 DNA methylation is a biomarker for the diagnosis of lung cancer in plasma. J Thorac Oncol 2011;6(10):1632-8.

13. Konecny M, Markus J, Waczulikova I, Dolesova L, Kozlova R, Repiska V, Novosadova H, Majer I. The value of SHOX2 methylation test in peripheral blood samples used for the differential diagnosis of lung cancer and other lung disorders. Neoplasma 2016;63(2):246-53.

14. Sidhar SK, Clark J, Gill S, Hamoudi R, Crew AJ, Gwilliam R, Ross M, Linehan WM, Birdsall S, Shipley J, Cooper CS. The t(X;1)(p11.2;q21.2) translocation in papillary renal cell carcinoma fuses a novel gene PRCC to the TFE3 transcription factor gene. Hum Mol Genet 1997;5(9):1333-8.

15. Horwitz M, Wiernik PH. Pseudoautosomal linkage of Hodgkin disease. Am J Hum Genet 1999;65(5):1413-22.

16. Lohr JG, Stojanov P, Lawrence MS, Auclair D, Chapuy B, Sougnez C, Cruz-Gordillo P, Knoechel B, Asmann YW, Slager SL, Novak AJ, Dogan A, Ansell SM, Link BK, Zou L, Gould J, Saksena G, Stransky N, Rangel-Escareño C, Fernandez-Lopez JC, Hidalgo-Miranda A Melendez-Zajgla J, Hernández-Lemus E, Schwarz-Cruz y Celis A, Imaz-Rosshandler I, Ojesina Al, Jung J, Pedamallu CS, Lander ES, Habermann TM, Cerhan JR, Shipp MA, Getz G, Golub TR. Discovery and prioritization of somatic mutations in diffuse large B-cell lymphoma (DLBCL) by whole-exome sequencing. Proc Natl Acad Sci U S A 2012;109(10):3879-84.

17. Pavlistova L, Izakova S, Zemanova Z, Bartuskova L, Langova M Malikova P, Michalova K. Rare congenital chromosomal aberration $\operatorname{dic}(X ; Y)(p 22.33 ; p 11.32)$ in a patient with primary myelofibrosis. Mol Cytogenet 2016;9(1):67.
18. Harvey RC, Mullighan CG, Chen IM, Wharton W, Mikhail FM, Carroll AJ, Kang H, Liu W, Dobbin KK, Smith MA, Carroll WL, Devidas M, Bowman WP, Camitta BM, Reaman GH, Hunger SP, Downing JR, Willman CL. Rearrangement of CRLF2 is associated with mutation of JAK kinases, alteration of IKZF1, Hispanic/Latino ethnicity, and a poor outcome in pediatric B-progenitor acute lymphoblastic leukemia. Blood 2010;115(26):5312-21.

19. Jia $M$, Wang $Z J$, Zhao HZ, Shen HP, Cheng YP, Luo ZB, Tang YM Prognostic significance of cytokine receptor-like factor 2 alterations in acute lymphoblastic leukemia: a meta-analysis. World J Pediatr 2015;11(2):126-33.

20. Chiaretti S, Brugnoletti F, Messina M, Paoloni F, Fedullo AL, Piciocch A, Elia L, Vitale A, Mauro E, Ferrara F, De Fabritiis P, Luppi M, Ronco F, De Propris MS, Raponi S, Kronnie GT, Vignetti M, Guarini A, Foà R. CRLF2 overexpression identifies an unfavourable subgroup of adult B-cell precursor acute lymphoblastic leukemia lacking recurrent genetic abnormalities. Leuk Res 2016:41:36-42.

21. Miao MH, Ji XQ, Zhang H, Xu J, Zhu H, Shao XJ. miR-590 promotes cell proliferation and invasion in T-cell acute lymphoblastic leukaemia by inhibiting RB1. Oncotarget 2016;7(26):39527-34.

22. Iqbal J, Nussenzweig A, Lubinski J, Byrski T, Eisen A, Bordeleau L, Tung NM, Manoukian S, Phelan CM, Sun P, Narod SA; Hereditary Breast Cancer Research Group. The incidence of leukaemia in women with BRCA1 and BRCA2 mutations: an International Prospective Cohort Study. Br J Cancer 2016;114(10):1160-4.

23. Sykes SM, Lane SW, Bullinger L, Kalaitzidis D, Yusuf R, Saez B, Ferraro F, Mercier F, Singh H, Brumme KM, Acharya SS, Scholl C, Tothova Z, Attar EC, Fröhling S, DePinho RA, Armstrong SA, Gilliland DG, Scadden DT. AKT/FOXO signaling enforces reversible differentiation blockade in myeloid leukemias. Cell 2011;146(5):697-708.

24. Burda P, Laslo P, Stopka T. The role of PU.1 and GATA-1 transcription factors during normal and leukemogenic hematopoiesis. Leukemia 2010;24(7):1249-57.

25. Hirschfeldova K, Florianova M, Kebrdlova V, Urbanova M, Stekrova J. Detection of SHOX gene aberrations in routine diagnostic practice and evaluation of phenotype scoring form effectiveness. J Hum Genet 2017;62(2):253-7.

26. Camitta BM, Rock A. Acute lymphoidic leukemia in a patient with thrombocytopenia/absent radii (Tar) syndrome. Am J Pediatr Hematol Oncol 1993;15(3):335-7.

27. Essig S, Li Q, Chen Y, Hitzler J, Leisenring W, Greenberg M, Sklar C, Hudson MM, Armstrong GT, Krull KR, Neglia JP, Oeffinger KC, Robison LL, Kuehni CE, Yasui Y, Nathan PC. Risk of late effects of treatment in children newly diagnosed with standard-risk acute lymphoblastic leukaemia: a report from the Childhood Cancer Survivor Study cohort. Lancet Oncol 2014;15(8):841-51. 